\title{
Pengaruh Lingkungan Kerja dan Beban Kerja Terhadap Kinerja Pegawai Pada Badan Pengelolaan Keuangan dan Aset Daerah Provinsi Jambi
}

\author{
Arman Syafa'at ${ }^{1 *}$, Andri Devita ${ }^{2}$ \\ ${ }^{1}$ Program Studi Manajemen, Universitas Muhammadiyah Jambi \\ ${ }^{2}$ Program Studi Pembangunan, Universitas Muhammadiyah Jambi \\ *Corresponding email: armansyafaat177@gmail.com
}

\begin{abstract}
The research entitled Effect Of The Work Environment And Work Load On Employee Performance In The Jambi Provincial Regional Financial And Assets Management Agency uses primary data which is presented in the form of a sample size for employees at the Regional Financial and Asset Management Agency of Jambi Province, namely Civil Servants who are 108 employees while the sample for honorary employees is 21 employees, so the total sample of employees is 129 people. The results showed that 1). Work Environment Variable (X1) Respondents' answers to the work environment variable averaged 3.65 or $73.01 \%$ with the criteria for a good work environment. Thus, it can be stated that "There is a significant influence between the work environment on employee performance at BPKAD Jambi Province". 2). Workload Variable (X2) Respondents' answers to the workload variable average 3.65 or $73.01 \%$ with the criteria of the workload is good or according to the distribution. Thus, it can be stated that: "There is a significant influence between workload and employee performance at BPKAD Jambi Province", it can be accepted the truth. 3). Effect of Variables X1 and X2 on Variable Y The results of the calculation F = 13,758 with (Sig) $0.000<0.05$, which means that Ho is rejected and Ha is accepted. There is a significant influence of work environment and workload on employee performance at BPKAD Jambi Province. With an $R$ square value of 0.756, which means that together the work environment and workload variables influence the low (depending on the value variation) of the employee performance variables at BPKAD Jambi Province by $75.60 \%$.
\end{abstract}

Keywords : Work Environment, Workload and Employee Performance

\section{Pendahuluan}

Sumber daya manusia yang berkualitas pada dasarnya ditentukan oleh indikator utama antara lain disiplin, kreatif, dan memiliki etos kerja yang tinggi. Seseorang dikatakan mempunyai kualitas sumber daya manusia yang tinggi jika ia dapat menunjukkan perilaku yang mencerminkan adanya etos kerja maupun kedisiplinan, kreatifitas yang tinggi dalam mengerjakan setiap tugas yang dimilikinya. Sebagai salah satu bagian dari organisasi Badan Pengelolaan Keuangan Dan Aset Daerah Provinsi Jambi, bertanggung jawab untuk mengatasi segala permasalahan yang terjadi dalam organisasi, termasuk stres pegawai. Hal ini dimaksudkan agar kinerja yang dicapai sesuai dengan harapan. Dilihat dari sumber daya manusia yang ada, jumlah pegawai yang ada adalah Pegawai Negeri Sipil sebanyak 159 orang, dan Pegawai Honorer sebanyak 31 orang

Berkenaan dengan tugas dan fungsi yang diemban serta dengan komposisi sumber daya manusia yang ada sebagaimana dikemukakan di atas, diasumsikan bahwa kinerja pegawai yang ada pada Badan Pengelolaan Keuangan Dan Aset Daerah Provinsi Jambi cukup tinggi. Berdasarkan pengamatan yang dilakukan terhadap pegawai di Badan Pengelolaan Keuangan Dan Aset Daerah Provinsi Jambi, terdapat beberapa perilaku pegawai yang diasumsikan akibat pada rendahnya kinerja dan/atau produkvitas kerja dari pegawai yang bersangkutan. Seyogyanya yang diharapkan bahwa keberadaan pegawai tersebut mampu mendukung dan meningkatkan produktivitas kerja organisasi. Namun berdasarkan pengamatan yang dilakukan, keberadaan pegawai yang ada tersebut memunculkan berbagai persoalan lain yang berhubungan langsung atau pun tidak langsung dan saling mempengaruhi kinerja pegawai. Namun demikian, dalam penelitian ini faktor yang diduga mempunyai pengaruh atau dampak secara langsung terhadap kinerja pegawai yaitu lingkungan kerjadan beban kerja.

Tujuan penelitian ini adalah untuk mengetahui apakah lingkungan kerja dan beban kerja secara parsial dan bersama-sama berpengaruh terhadap kinerja pegawai pada Badan Pengelolaan Keuangan Dan Aset Daerah Provinsi Jambi?

\section{Metode}

Penelitian ini termasuk jenis penelitian korelasional karena akan membahas tentang pengaruh dari beberapa variabel yaitu Lingkungan Kerja Dan Beban Kerja Terhadap Kinerja Pegawai Pada Badan Pengelolaan Keuangan Dan Aset Daerah Provinsi Jambi tahun 2020. Sedangkan penelitian ini termasuk penelitian deskriptif karena selain untuk mencari pengaruh dan hubungan antar variabel juga akan dideskripsikan, digambarkan atau dilukiskan secara sistematis, faktual dan akurat mengenai fakta-fakta, sifat-sifat serta hubungan antara fenomena yang akan diselidiki Jenis data dalam penelitian ini adalah : Data Kuantitatif yaitu Data yang diperoleh dalam bentuk angka yang dapat dihitung. Data ini diperoleh dari perhitungan kuesioner yang berhubungan dengan masalah yang dibahas dalam 
penelitian ini (Sugiyono, 2005). Dalam penelitian ini menggunakan dua sumber data yaitu : Data primer adalah data yang diperoleh secara langsung dari sumber asli (tanpa perantara). Data primer dikumpulkan sendiri oleh peneliti untuk menjawab penelitiannya secara khusus. Data primer yang ada dalam penelitian ini merupakan hasil penyebaran kuesioner pada sampel yang telah ditentukan. Dari kuesioner tersebut akan didapat data mengenai bagaimana tanggapan responden mengenai variabel-variabel yang ada dalam penelitian ini (Sugiyono, 2005).

Jumlah sampel untuk pegawai pada Badan Pengelolaan Keuangan Dan Aset Daerah Provinsi Jambi yaitu Pegawai Negeri Sipil adalah 108 pegawai sedangkan sampel untuk pegawai honorer adalah 21 pegawai, jadi jumlah sampel pegawai seluruhnya adalah 129 orang. Analisis kuantitatif akan dilakukan untuk menguji pengaruh beban kerja dan lingkungan kerja terhadap kinerja Pegawai Badan Pengelolaan Keuangan Dan Aset Daerah Provinsi Jambi. Persamaan Regresi Linier Berganda yaitu sebagai berikut:

$\mathrm{Y}=\alpha+\beta_{1} \mathrm{X}_{1}+\beta_{2} \mathrm{X}_{2}+\mathrm{e}$

Keterangan: $Y=$ Variabel Kinerja Pegawai; $X_{1}=$ Variabel Lingkungan Kerja; $\mathrm{X}_{2}=$ Variabel Beban Kerja; $\alpha=$ Intercep; $\beta_{1,2}=$ Koefisien regresi; $\mathrm{e}=$ Tingkat Kesalahan

\section{Hasil}

Variabel Lingkungan Kerja (X1)

Tabel 1.

Uji Validitas Variabel Lingkungan Kerja

\begin{tabular}{|c|c|c|c|c|}
\hline & Scale Mean if Item Deleted & Scale Variance if Item Deleted & Corrected Item-Total Correlation & Cronbach's Alpha if Item Deleted Ket. \\
\hline VAR00001 & \begin{tabular}{|r|}
35.4667 \\
\end{tabular} & $\begin{array}{r}149.706 \\
\end{array}$ & $\begin{array}{rr} & 719 \\
\end{array}$ & 941 Valid \\
\hline VAR00002 & 34.8000 & 173.821 & .143 & .956 Tidak Valid \\
\hline VAR00003 & 35.5000 & 142.259 & .873 & .935 Valid \\
\hline V AR00004 & 35.5333 & 149.568 & .753 & .939 Valid \\
\hline VAR00005 & 35.4333 & 152.392 & .677 & .942 Valid \\
\hline VAR00006 & 35.4000 & 139.766 & .944 & .931 Valid \\
\hline VAR00007 & 35.4667 & 140.051 & .922 & .932 Valid \\
\hline VAR00008 & 35.6333 & 147.620 & .674 & .943 Valid \\
\hline VAR00009 & 35.2000 & 147.683 & .816 & .937 Valid \\
\hline VAR00010 & 35.2667 & 143.857 & .828 & .936 Valid \\
\hline VAR00011 & 35.3000 & 143.803 & .854 & .935 Valid \\
\hline
\end{tabular}

Sumber: olahan data

Tabel 1, diperoleh Corrected Item-Total Correlation terdapat 1 (satu) pernyataan yang tidak valid, yakni nomor pernyataan 2 (dua) dengan skor sebesar 0.143. Sedangkan skor standar yang ditetapkan dalam $r$ tabel sebesar 0.361. Untuk pernyataan lainnya dari kuesioner variabel lingkungan kerja dapat dipergunakan. Oleh kerena itu, maka pada perhitungan sampel keseluruhan, pernyataan nomor 2 (dua) tersebut sudah tidak dipergunakan lagi (tidak disampaikan kepada responden), sehingga jumlah pernyataan yang dipergunakan dalam variabel ini sebanyak 10 (sepuluh) pernyataan, karena Corrected Item-Total Correlation $0,143<0.361$.

Tabel 2 di atas, diperoleh perhitungan dari jawaban responden terhadap variabel lingkungan kerja rata-rata sebesar 3,65 atau 73,01\% dengan kriteria lingkungan kerja baik. Hal tersebut berarti bahwa 73,01\% responden menyatakan bahwa lingkungan kerja BPKAD Provinsi Jambi sudah baik sehingga perlu dipertahankan dan ditingkatkan kembali agar dapat meningkatkan kinerja pegawai BPKAD Provinsi Jambi. Selanjutnya, dari beberapa pernyataan yang diajukan terdapat 1 (satu) pernyataan yang nilai rata-ratanya dibawah nilai rata-rata keseluruhan, yaitu pernyataan 5 yang berkenaan dengan fasilitas kerja. Hal ini perlu mendapat perhatian pihak terkait, sehingga lingkungan kerja akan semakin baik dimasa yang akan datang.

Tabel 2.

Tanggapan Responden Terhadap Variabel Lingkungan Kerja

\begin{tabular}{|c|c|c|c|}
\hline Pernyataan & Rata-Rata & Persentase (\%) & Kriteria \\
\hline \multicolumn{4}{|l|}{ a. Hubungan Kerja } \\
\hline 1. Ketika saya mendapat kesulitan dalam penyelesaian pekerjaan, saya selalu dibantu oleh pegawai lainnya & 3,68 & 73,6 & Lingkungan Kerja Baik \\
\hline 2. Atasan saya bersedia mendengarkan masalah yang berkaitan dengan pekerjaan pegawai & 3,60 & 71,9 & Lingkungan Kerja Baik \\
\hline 3. Atasan saya menunjukkan perhatian yang besar terhadap pekerjaan pegawai & 3,59 & 71,8 & Lingkungan Kerja Baik \\
\hline 4. Atasan saya perduli dengan kondisi perkembangan pegawai & 3,83 & 76,6 & Lingkungan Kerja Baik \\
\hline \multicolumn{4}{|l|}{ b. Fasilitas Kerja } \\
\hline 1. Organisasi telah menggunakan teknologi yang memadai dalam penyelesaian pekerjaan & 3,41 & 68,2 & Lingkungan Kerja Kurang Baik \\
\hline 2. Untuk menunjang pekerjaan pegawai, organisasi menyediakan alat tulis kantor yang memadai & 3,78 & 75,7 & Lingkungan Kerja Baik \\
\hline 3. Alat kantor yang dibutuhkan pegawai banyak yang tidak berfungsi sebagaimana mestinya & 3,75 & 75 & Lingkungan Kerja Baik \\
\hline \multicolumn{4}{|l|}{ c. Tunjangan Kerja } \\
\hline 1. Orgabisasi memberikan bonsus kaitannya dengan penyelesaian pekerjaan & 3,67 & 73,3 & Lingkungan Kerja Baik \\
\hline 2. Organisasi selalu memberikan tunjangan hari raya & 3,59 & 71,8 & Lingkungan Kerja Baik \\
\hline 3. Organisasi telah mendaftarkan karyawan dalam asuransi & 3,7 & 74 & Lingkungan Kerja Baik \\
\hline Rata-rata Keseluruhan & 3.65 & 73.01 & Lingkungan Kerja Baik \\
\hline
\end{tabular}

Sumber: olahan data 


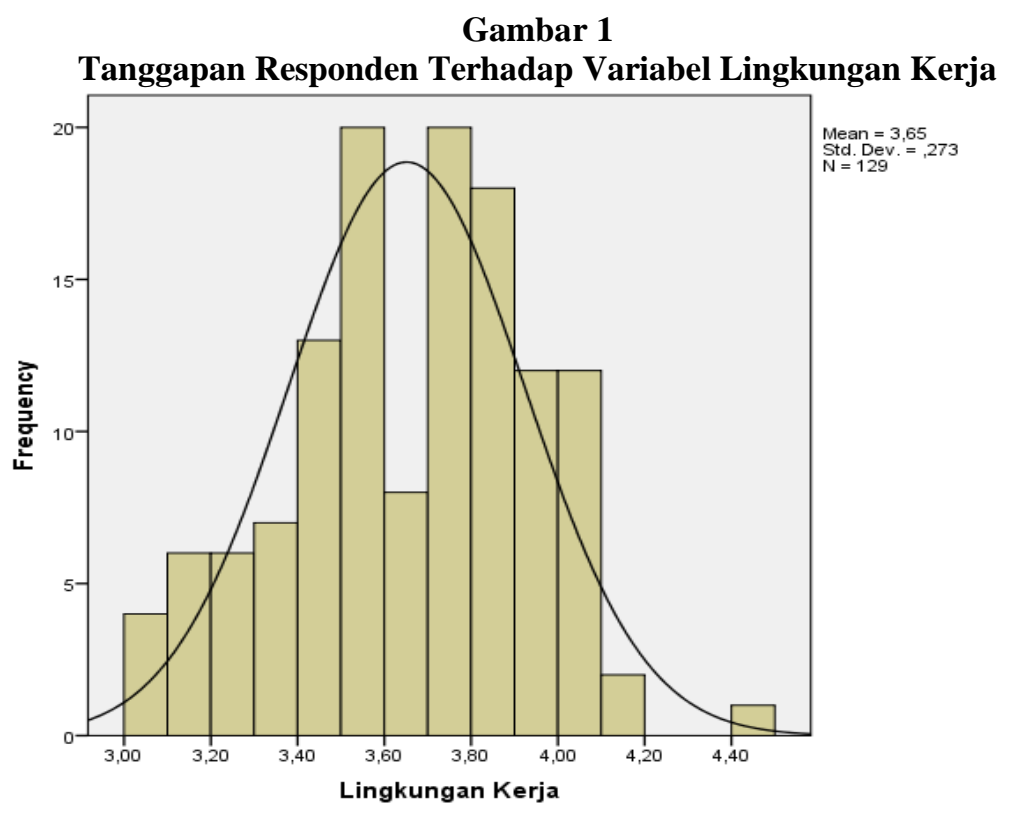

Sumber: olahan data

Berdasarkan gambar 1 tersebut terlihat bahwa skor rata-rata (Mean) sebasar 3,65 dengan standar deviasi sebesar 0,273, yang berarti pula bahwa sebaran jawaban responden terbanyak terhadap pernyataan variabel lingkungan kerja berada pada $(3,65$ atau $73,01 \%)$ yang berarti responden dominan setuju dengan kriteria baik terhadap pernyataan-pernyataan dari lingkungan kerja. Secara keseluruhan dapat disimpulkan bahwa lingkungan kerja pada BPKAD Provinsi Jambi sudah baik, sehingga perlu dipertahankan dan ditingkatkan.

Variabel Beban Kerja (X2)

Tabel 3

Uji Validitas Variabel Beban Kerja

\begin{tabular}{|c|c|c|c|c|c|}
\hline & Scale Mean if Item Deleted & Scale Variance if Item Deleted & Corrected Item-Total Correlation & Cronbach's Alpha if Item Deleted & Ket. \\
\hline VAR00001 & 38.8333 & 80.213 & .455 & 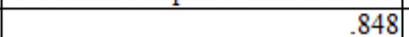 & Valid \\
\hline VAR00002 & 38.9667 & 77.068 & .630 & .836 & Valid \\
\hline VAR00003 & 38.9333 & 77.789 & .493 & .846 & Valid \\
\hline VAR00004 & 38.8333 & 77.868 & .550 & .841 & Valid \\
\hline VAR00005 & 38.6333 & 79.068 & .480 & .846 & Valid \\
\hline VAR00006 & 39.1000 & 71.059 & .685 & .829 & Valid \\
\hline VAR00007 & 38.9000 & 74.714 & .604 & .837 & Valid \\
\hline VAR00008 & 38.6667 & 78.023 & .590 & .839 & Valid \\
\hline VAR00009 & 38.7333 & 78.271 & .595 & .838 & Valid \\
\hline VAR00010 & 38.7000 & 79.597 & .493 & .845 & Valid \\
\hline VAR00011 & 38.7000 & 80.079 & .405 & .853 & Valid \\
\hline
\end{tabular}

Sumber: olahan data

Tabel 4, diperoleh perhitungan dari jawaban responden terhadap variabel beban kerja rata-rata sebesar 3.65 atau $73.01 \%$ dengan kriteria beban kerja sudah baik atau sesuai pembagiannya. Hal tersebut berarti bahwa $73.01 \% \%$ responden bahwa beban kerja BPKAD Provinsi Jambi sudah sesuai sehingga perlu dipertahankan dan ditingkatkan kembali agar dapat meningkatkan kinerja pegawai BPKAD Provinsi Jambi. Selanjutnya, dari beberapa pernyataan yang diajukan terdapat 1 (satu) pernyataan yang nilai rata-ratanya dibawah nilai rata-rata keseluruhan, yaitu pernyataan 6 berkenaan dengan beban usaha mental/beban pekerjaan. Pernyataan 6 tersebut perlu mendapat perhatian pihak terkait, sehingga beban kerja (pembagian pekerjaan) yang diberikan kepada pegawai akan semakin baik dimasa yang akan datang. 
Arman Syafa'at dan Andri Devita, Pengaruh Lingkungan Kerja dan Beban Kerja Terhadap Kinerja Pegawai pada Badan Pengelolaan Keuangan dan Aset Daerah Provinsi Jambi

Tabel 4

Tanggapan Responden Terhadap Variabel Beban Kerja

\begin{tabular}{|c|c|c|c|}
\hline Pernyataan & Rata-Rata & Persentase (\%) & Kriteria \\
\hline \multicolumn{4}{|l|}{ a. Beban usaha mental/ beban pekerjaan } \\
\hline 1. Beban pekerjaan tidak jelas mengenai cakupan atau ruang lingkup pekerjaan saya & 3.66 & 73.18 & Beban kerja sesuai \\
\hline 2. Beban pekerjaan yang terlalu berat yang tidak mungkin diselesaikan selama jam kerja & 3.53 & 70.54 & Beban kerja sesuai \\
\hline 3. Beban pekerjaan dipantau dengan sangat ketat pekerjaannya oleh atasan atau pegawai lainnya & 3.63 & 72.56 & Beban kerja sesuai \\
\hline 4. Beban pekerjaan tidak m ampu mem enuhi atau menyel esaikan tuntutan tugas dari berbagai or ang yang berhubungan dengan saya & 3.67 & 73.49 & Beban kerja sesuai \\
\hline \multicolumn{4}{|l|}{ b. Beban Waktu } \\
\hline 1. Waktu istirahat saya kurang dibandingkan w aktu untuk menjalank an pekerjaan & 3.91 & 78.14 & Beban kerja sesuai \\
\hline 2. Saya sering mendapat tugas/pekerjaan yang harus diselesaikan di luar jam kerja & 3.43 & 68.53 & Beban kerja kurang sesuai \\
\hline 3. Selalu ada pembagian kerja ber glir jika ada pekerjaan di luar jam kerja & 3.73 & 74.57 & Beban kerja sesuai \\
\hline \multicolumn{4}{|l|}{ c. Beban Psikologis } \\
\hline 1. Saya kadangkala melanggar atur an atau kebijakan lembaga demi m enjalankan tugas & 3.81 & 76.12 & Beban kerja sesuai \\
\hline 2. Pekerjaan meruuntut saya menyel es aikan tugas yang seharusnya dikerjakan secara berbeda & 3.66 & 73.18 & Beban kerja sesuai \\
\hline 3. Saya menerim a penugasan yang berbeda-beda dari dua orang atasan pegaw ai atau lebih & 3.52 & 70.39 & Beban kerja sesuai \\
\hline 4. Saya sering mengerjak an hal-hal yang tidak perlu & 3.62 & 72.40 & Beban kerja sesuai \\
\hline Rata-rata Keseluruhan & 3.65 & 73.01 & Beban kerja sesuai \\
\hline
\end{tabular}

Sumber: olahan data

Gambar 2

Tanggapan Responden Terhadap Variabel Beban Kerja

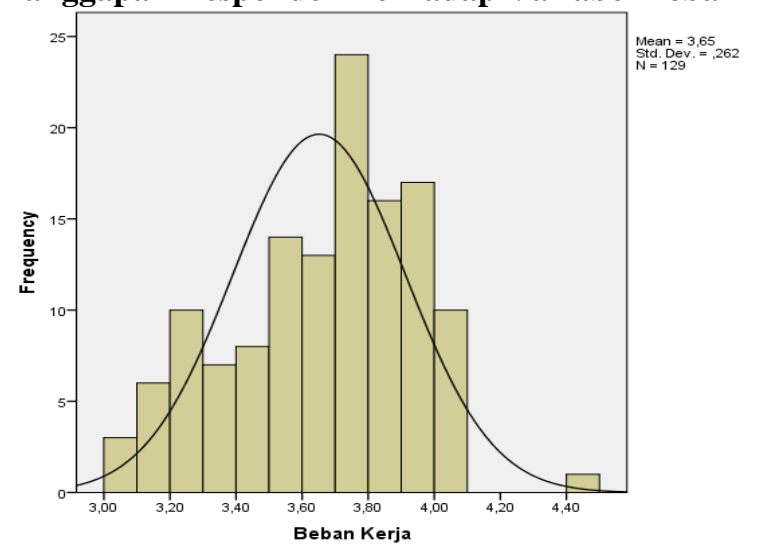

Sumber: olahan data

Berdasarkan gambar 2 tersebut terlihat bahwa skor rata-rata (Mean) sebasar 3,65 dengan standar deviasi sebesar 0.262 , yang berarti pula bahwa sebaran jawaban responden terbanyak terhadap pernyataan variabel beban kerja berada pada $(3,65$ atau 73,01 \%). Secara keseluruhan dapat disimpulkan bahwa beban kerja pada pegawai BPKAD Provinsi Jambi sudah baik, sehingga perlu dipertahankan dan ditingkatkan.

Variabel Kinerja Pegawai (Y)

Tabel 5.

Uji Validitas Variabel Kinerja Pegawai

\begin{tabular}{|c|c|c|c|c|c|}
\hline & Scale Mean if Item Deleted & Scale Variance if Item Deleted & Corrected Item-Total Correlation & Cronbach's Alpha if Item Deleted & Ket. \\
\hline VAR00001 & 36.1333 & 56.464 & \begin{tabular}{|r}
543 \\
\end{tabular} & $\begin{array}{rr} & 875 \\
\end{array}$ & Valid \\
\hline VAR00002 & 36.1000 & 55.197 & .707 & .864 & Valid \\
\hline VAR00003 & 35.9333 & 58.271 & .573 & .872 & Valid \\
\hline VAR00004 & 36.0000 & 53.379 & .735 & .861 & Valic \\
\hline VAR00005 & 35.7667 & 57.082 & .609 & .870 & Valic \\
\hline VAR00006 & 35.5000 & 60.397 & .509 & .876 & Valic \\
\hline VAR00007 & 36.2667 & 55.306 & .624 & .869 & Valic \\
\hline VAR00008 & 36.3000 & 54.976 & .611 & .870 & Valic \\
\hline VAR00009 & 35.9000 & 56.231 & .581 & .872 & Valic \\
\hline VAR00010 & 35.6333 & 58.378 & .440 & .881 & Valic \\
\hline VAR00011 & 36.1333 & 56.464 & .621 & .869 & Valic \\
\hline
\end{tabular}

Sumber: olahan data 
Arman Syafa'at dan Andri Devita, Pengaruh Lingkungan Kerja dan Beban Kerja Terhadap Kinerja Pegawai pada Badan Pengelolaan Keuangan dan Aset Daerah Provinsi Jambi

Tabel 6

Tanggapan Responden Terhadap Variabel Kinerja Pegawai

\begin{tabular}{|c|c|c|c|}
\hline Pernyataan & Rata-Rata & Persentase (\%) & Kriteria \\
\hline \multicolumn{4}{|l|}{ a. Prestasi kerja } \\
\hline 1. Hasil pekerjaan yang dicapai selalu sesuai dengan target yang ditetapkan & 3.71 & 74.26 & Baik \\
\hline 2. Hasil pekerjaan yang dicapai mampu memberikan kepuasan pada instansi & 3.57 & 71.47 & Baik \\
\hline \multicolumn{4}{|l|}{ b. Tanggung Jawab } \\
\hline 1. Pegawai bertanggung jawab atas pekerjaan yang dilakukan & 3.71 & 74.11 & Baik \\
\hline 2. Dalam bekerja pegawai selalu melaksanakannya dan selesai tepat waktu se suai rencana dan hasilnya baik & 3.67 & 73.49 & Baik \\
\hline \multicolumn{4}{|l|}{ c. Kesetiaan } \\
\hline 1. Pegawai merasa bertanggung jawab penuh atas pekerjaan yang diberikan oleh pimpinan & 3.86 & 77.21 & Baik \\
\hline \multicolumn{4}{|l|}{ d. Kerjasama } \\
\hline 1. Pegawai mampu bekerja sama dalam melakukan pekerjaan. & 3.43 & 68.68 & Kurang B aik \\
\hline \multicolumn{4}{|l|}{ e. Prakarsa } \\
\hline 1. Para pegawai mempunyai inisiatif yang baik untuk memajukan pekerjan. & 3.72 & 74.42 & Baik \\
\hline 2. Para pegawai mempunyai ide-ide dan saran yang baik untuk instansi & 3.64 & 72.71 & Baik \\
\hline \multicolumn{4}{|l|}{ f. Ketaatan } \\
\hline 1. Pegawai selalu taat terhadap peraturan-peraturan kantor & 3.64 & 72.87 & Baik \\
\hline \multicolumn{4}{|l|}{ g. Kejujuran } \\
\hline 1. Pegawai tidak pernah berbohong atas capaian kerjanya & 3.57 & 71.47 & Baik \\
\hline 2. Pegawai membuat laporan kerja se suai dengan hasil kerja yang ada & 3.64 & 72.71 & Baik \\
\hline Rata-rata Keseluruhan & 3.65 & 73.04 & Kinerja B aik \\
\hline
\end{tabular}

Sumber: olahan data

Secara keseluruhan dari Tabel 6 tersebut di atas, untuk variabel kinerja diperoleh nilai rata-rata sebesar 3,60 atau $73,04 \%$ yang berarti responden dominan setuju dengan kriteria baik terhadap pernyataan-pernyataan dari indikator kinerja. Berdasarkan data pernyataan kuesioner dari jawaban responden tentang kinerja pegawai maka dapat dibuat secara grafik sebaran penilaian responden tentang kinerja pegawai adalah sebagai berikut:

Gambar 3

Tanggapan Responden Terhadap Variabel Kinerja Pegawai

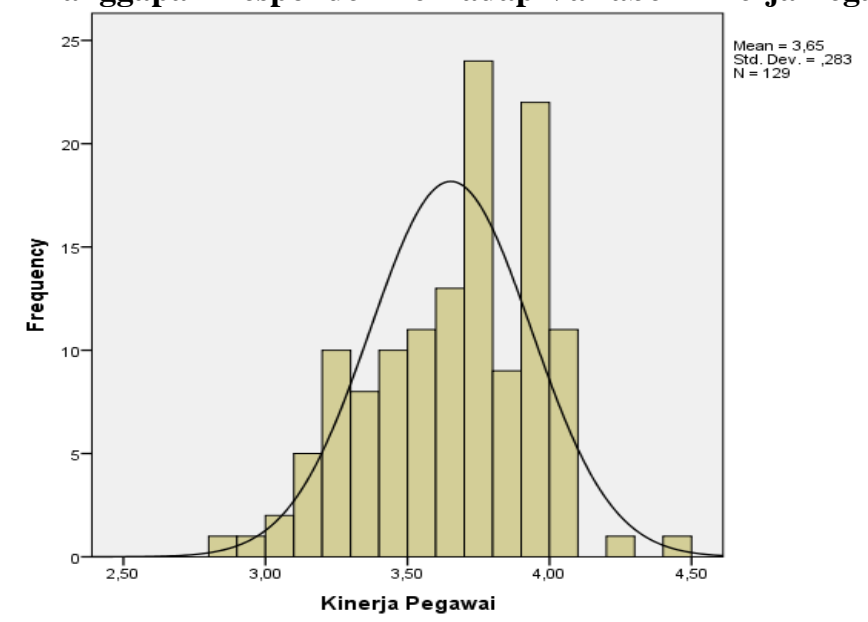

Sumber: olahan data

Berdasarkan gambar 3 tersebut terlihat bahwa skor rata-rata (Mean) sebasar 3,65 dengan standar deviasi sebesar 0.283, yang berarti pula bahwa sebaran jawaban responden terbanyak terhadap pernyataan variabel kinerja pegawai berada pada $(3,65$ atau $73,04 \%)$. Secara keseluruhan dapat disimpulkan bahwa kinerja pada pegawai BPKAD Provinsi Jambi sudah baik, sehingga perlu dipertahankan dan ditingkatkan.

Tabel 7

Coefficients $^{\mathrm{a}}$

\begin{tabular}{|c|c|c|c|c|c|c|}
\hline \multirow{3}{*}{\multicolumn{2}{|c|}{ Model }} & \multirow{2}{*}{\multicolumn{2}{|c|}{ Unstandardized Coefficients }} & \multirow{3}{*}{$\begin{array}{c}\text { Standardized Coefficients } \\
\text { Beta }\end{array}$} & \multirow{3}{*}{$\mathrm{t}$} & \multirow{3}{*}{ Sig. } \\
\hline & & & & & & \\
\hline & & $\mathrm{B}$ & Std. Error & & & \\
\hline \multirow{3}{*}{1} & (Constant) & $-1,856$ & ,391 & & $-4,748$ & ,000 \\
\hline & Lingkungan Kerja & ,195 & ,062 & ,292 & 3,161 & ,002 \\
\hline & Beban Kerja & ,439 & ,091 & ,406 & 4,831 &, 000 \\
\hline
\end{tabular}

Sumber: olahan data 
Arman Syafa'at dan Andri Devita, Pengaruh Lingkungan Kerja dan Beban Kerja Terhadap Kinerja Pegawai pada Badan Pengelolaan Keuangan dan Aset Daerah Provinsi Jambi

Berdasarkan tabel 7 tersebut, maka diperoleh persamaan regresi sebagai berikut:

$\mathrm{Y}=-1,856+0,195 \mathrm{X} 1+0,439 \mathrm{X} 2+\mathrm{e}$

Hasil perhitungan SPSS sebagaimana terlihat pada tabel 5.10 dengan taraf signifikansi 0.05, maka dari kedua variabel bebas (lingkungan kerja dan beban kerja) tersebut terhadap variabel tidak bebas (kinerja pegawai) pada badan pengelolaan keuangan dan aset daerah Provinsi Jambi, diperoleh hasil signifikansi adalah variabel lingkungan kerja (Sig) $0,002<0.05$, yang berarti signifikan terhadap kinerja pegawai dan untuk variabel beban kerja (Sig) $0.000<0.05$ yang berarti signifikan. Oleh karena itu, persamaan akhir yang diperoleh dalam penelitian ini berdasarkan taraf signifikansi yang diperoleh menjadi :

$\mathrm{Y}=-1,856+0,195 \mathrm{X} 1+0,439 \mathrm{X} 2+\mathrm{e}$

Persamaan regresi tersebut dapat disimpulkan bahwa lingkungan kerja dan beban kerja memiliki pengaruh yang positif dan signifikan terhadap kinerja kerja pegawai BPKAD Provinsi Jambi. Dengan demikian diperoleh $\alpha=$ Intercep sebesar -1,856 dapat diartikan bahwa apabila variabel lingkungan kerja dan beban kerja tidak mengalami perubahan dalam artian tetap/konstan maka kinerja pegawai pada BPKAD Provinsi Jambi akan menurun sebear 1,856 $\%$. Untuk nilai koefisien regresi $\left(\beta_{1}\right) \mathrm{X}_{1}$ yaitu sebesar 0,195 dapat diartikan nilai lingkungan kerja mengalami perbaikan atau peningkatan $1 \%$ maka kinerja pegawai pada BPKAD Provinsi Jambi akan meningkat sebesar 0,195\%. Dan juga untuk ilai koefisien regresi $\left(\beta_{2}\right) \mathrm{X}_{2}$ yaitu sebesar 0,439 dapat diartikan nilai beban kerja mengalami perbaikan atau peningkatan $1 \%$ maka kinerja pegawai pada BPKAD Provinsi Jambi akan meningkat sebesar 0,439\%. Persamaan regresi tersebut, dapat juga disimpulkan bahwa variabel beban kerja secara relatif berkontribusi lebih besar dibandingkan dengan variabel lingkungan kerja dalam mempengaruhi peningkatan kinerja pegawai pada BPKAD Provinsi Jambi.

Tabel 8.

Koefisien Korelasi Masing-Masing Variabel

\begin{tabular}{|c|c|c|c|c|}
\hline & & Lingkungan Kerja & Beban Kerja & Kinerja Pegawai \\
\hline \multirow{3}{*}{ Lingkungan Kerja } & Pearson Correlation & 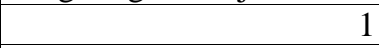 & ,737 &, $830^{* * *}$ \\
\hline & Sig. (2-tailed) & & ,095 &, 002 \\
\hline & $\mathrm{N}$ & 129 & 129 & 129 \\
\hline \multirow{3}{*}{ Beban Kerja } & Pearson Correlation & ,737 & 1 & ,908* \\
\hline & Sig. (2-tailed) & ,095 & &, 000 \\
\hline & $\mathrm{N}$ & 129 & 129 & 129 \\
\hline \multirow{3}{*}{ Kinerja Pegawai } & Pearson Correlation &, $830^{* *}$ & ,908* & 1 \\
\hline & Sig. (2-tailed) &, 002 &, 000 & \\
\hline & $\mathrm{N}$ & 129 & 129 & 129 \\
\hline
\end{tabular}

Sumber: olahan data

Berdasarkan tabel 8 tersebut, maka dapat diuraikan hubungan variabel yang ada sebagai berikut:

1. Koefeisien korelasi antara variabel lingkungan kerja (X1) dengan variabel kinerja pegawai pada BPKAD (Y) Provinsi Jambi sebesar 0.830, yang berarti memiliki hubungan kuat dan positif signifikan karena nilai (Sig) variabel lingkungan kerja diperoleh sebesar $0.002<0.05$.

2. Koefeisien korelasi antara variabel beban kerja (X2) dengan variabel kinerja pegawai pada BPKAD (Y) Provinsi Jambi sebesar 0.908, yang berarti memiliki hubungan sangat kuat dan positif serta signifikan karena nilai (Sig) variabel beban kerja diperoleh sebesar $0.000<0.05$.

Tabel 9

Summary

\begin{tabular}{|l|r|r|r|r|}
\hline \multicolumn{1}{|c|}{ Model } & R & R Square & Adjusted R Square & \multicolumn{2}{c|}{ Std. Error of the Estimate } \\
\hline 1 &, $870^{\mathrm{a}}$ &, 756 &, 675 & 1,05861 \\
\hline
\end{tabular}

Sumber: olahan data

Berdasarkan tabel 9 variabel Lingkunga kerja $\left(\mathrm{X}_{1}\right)$ dan beban kerja $(\mathrm{X} 2)$ memiliki hubungan yang kuat dan positif dengan kinerja pegawai pada BPKAD Provinsi Jambi $\left(r_{\mathrm{X} 1 \mathrm{X} 2 \mathrm{Y}}=0.870\right)$ atau sebesar 87,00 \% . Dari Tabel 5.12 tersebut terlihat bahwa nilai $R$ square sebesar 0,756 yang memiliki arti bahwa secara bersama-sama variabel lingkungan kerja dan beban kerja pengaruh terhadap tinggi rendahnya (tergantung variasi nilai) variabel kinerja pegawai pada Badan Pengelelolaan Keuangan dan Aset Daerah Provinsi Jambi sebesar 75,60\%, sedangkan sisa 
Arman Syafa'at dan Andri Devita, Pengaruh Lingkungan Kerja dan Beban Kerja Terhadap Kinerja Pegawai pada Badan Pengelolaan Keuangan dan Aset Daerah Provinsi Jambi

dipengaruhi di luar variabel yang telah ditentukan sebesar $24.40 \%$ kinerja pegawai disebabkan oleh variabel-variabel lain yang tidak dimasukan ke dalam model penelitian.

\section{Uji t}

Tabel 10.

Uji t- Test Pada Coefficients ${ }^{a}$

\begin{tabular}{|l|l|r|rr|}
\hline \multicolumn{2}{|c|}{ Model } & $\mathrm{t}$ & \multicolumn{1}{c|}{ Sig. } \\
\hline \multirow{3}{*}{1} & (Constant) & & $-4,748$ &, 000 \\
& Lingkungan Kerja & 3,161 &, 002 \\
& Beban Kerja & &, 000 \\
\hline
\end{tabular}

Sumber: olahan data

Berdasarkan hasi perhitungan SPSS pada tabel 10, diperoleh nilai $\mathrm{t}=3,161$ dengan $(\operatorname{Sig})=0.002$. Hal ini menunjukan bahwa $0.002<\alpha=0.05$ yang berarti siginifikan, dengan kata lain Ho ditolak Ha diterima. Dengan demikian, hipotesis dapat dinyatakan bahwa ada pengaruh signifikan antara lingkungan kerja terhadap kinerja pegawai pada BPKAD Provinsi Jambi” dapat diterima kebenarannya.

Hasil perhitungan SPSS pada tabel 10, diperoleh $\mathrm{t}=4,831$ dengan $(\mathrm{Sig})=0.000$. Hal ini menunjukan bahwa $0.000<\alpha=0.05$ yang berarti memiliki pengaruh siginifikan, dengan kata lain Ho ditolak Ha diterima. Dengan demikian, hipotesis dapat dinyatakan bahwa ada pengaruh signifikan antara beban kerja terhadap kinerja pegawai pada BPKAD Provinsi Jambi”, dapat diterima kebenarannya.

Uji F

Tabel 11

Uji F-Test Pada ANOVA ${ }^{a}$

\begin{tabular}{|c|c|c|c|c|c|c|}
\hline \multicolumn{2}{|c|}{ Model } & Sum of Squares & $\mathrm{df}$ & Mean Square & $\mathrm{F}$ & Sig. \\
\hline & Regression & 1,839 & 2 & ,920 & \multirow[t]{3}{*}{13,758} & \multirow[t]{3}{*}{, $000^{\mathrm{b}}$} \\
\hline 1 & Residual & 8,422 & 126 & 067 & & \\
\hline & Total & 10,262 & 128 & & & \\
\hline
\end{tabular}

Sumber: olahan data

Berdasarkan tabel 11 terlihat bahwa hasil perhitungan SPSS diperoleh $\mathrm{F}=13,758$ dengan ( Sig) $0.000<0.05$, yang berarti juga bahwa Ho ditolak dan Ha diterima. Jadi secara bersama-sama hipotesis yang diperoleh bahwa "Ada pengaruh signifikan lingkungan kerja dan beban kerja terhadap kinerja pegawai pada BPKAD Provinsi Jambi dapat diterima kebenarannya".

\section{Simpulan} berikut:

Berdasarkan hasil pengolahan data, analisa dan pembahasan yang telah dilakukan, dapat disimpulkan sebagai

1. Jawaban responden terhadap variabel lingkungan kerja rata-rata sebesar 3.65 atau $73,01 \%$ dengan kriteria lingkungan kerja baik. Koefisien korelasi antara variabel lingkungan kerja (X1) dengan variabel kinerja pegawai (Y) sebesar 0.830, yang berarti memiliki hubungan kuat dan positif signifikan karena nilai (Sig) variabel lingkungan kerja diperoleh sebesar $0.002<0.05$. Variabel Lingkungan Kerja memiliki nilai $t=3,161$ dengan $($ Sig $)=0.002$. Hal ini menunjukan bahwa $0.002<\alpha=0.05$ yang berarti siginifikan, dengan kata lain Ho ditolak Ha diterima. Dengan demikian, hipotesis dapat dinyatakan bahwa ada pengaruh signifikan antara lingkungan kerja terhadap kinerja pegawai pada BPKAD Provinsi Jambi.

2. Jawaban responden terhadap variabel beban kerja rata-rata sebesar 3.65 atau $73.01 \%$ dengan kriteria beban kerja sudah baik atau sesuai pembagiannya. Koefeisien korelasi antara variabel beban kerja (X2) dengan variabel kinerja pegawai (Y) sebesar 0.908, yang berarti memiliki hubungan sangat kuat dan positif serta signifikan karena nilai (Sig) variabel beban kerja diperoleh sebesar $0.000<0.05$. Variabel Beban Kerja memiliki nilai $\mathrm{t}=4.831$ dengan (Sig) $=0.000$. Hal ini menunjukan bahwa $0.000<\alpha=0.05$ yang berarti memiliki pengaruh siginifikan, dengan kata lain Ho ditolak Ha diterima. Dengan demikian, hipotesis dapat dinyatakan bahwa ada pengaruh signifikan antara beban kerja terhadap kinerja pegawai pada BPKAD Provinsi Jambi", dapat diterima kebenarannya.

3. Hasil perhitungan diperoleh $\mathrm{F}=13.758$ dengan $(\mathrm{Sig}) 0.000<0.05$, yang berarti juga bahwa Ho ditolak dan Ha diterima. Jadi secara bersama-sama hipotesis yang diperoleh bahwa ada pengaruh signifikan lingkungan kerja dan 
beban kerja terhadap kinerja pegawai pada BPKAD Provinsi Jambi dapat diterima kebenarannya". Dengan nilai $R$ square sebesar 0.756 yang memiliki arti bahwa secara bersama-sama variabel lingkungan kerja dan beban kerja pengaruh terhadap tinggi rendahnya (tergantung variasi nilai) variabel kinerja pegawai pada BPKAD Provinsi Jambi sebesar $75.60 \%$, sedangkan sisanya di luar variabel yang telah ditentukan sebesar $24.40 \%$ kinerja pegawai disebabkan oleh variabel-variabel lain yang tidak dimasukan ke dalam model penelitian.

\section{Daftar Pustaka}

Amirullah. 2010. Hubungan Lingkungan Kerja Terhadap Kinerja Karyawan. Seputar Penelitian.blogspot.co. Anasthasia, S. 2007. Influence Of Ability and Motivation to Government. http://www.fisip.undip.ac.id/in/index.php?par=skripsiview\&pidskripsi=19.

Arikunto, Suharsimi. 2003. Prosedur Penelitian, Suatu Pendekatan Praktek. Cetakan Kesebelas Edisi Revisi IV. PT. Rineka Cipta Jakarta.

Burhanuddin, Afid. 2013. Penelitian Kuantitatif dan Kualitatif. Afidburhanuddin.wordpress.com

Cokroaminoto, 2007, Membangun Kinerja (Memaknai Kinerja Karyawan), Google/15012008/cokroaminoto.wordpress.com/20070523/memaknai-kinerja-karyawan.

Damanik, Caroline Agnes. 2013. Pengaruh Kejelasan Peran, Beban Kerja dan Status Pegawai Terhadap Stres Kerja Pada PT. Bank Lampung Cabang Pembantu Kartini, Skripsi, Universitas Bandar Lampung.

Devianggreini90.wordpress.com. 2011. Definisi Stres, Keterkaitan Stres Dengan Lingkungan dan Pengaruh Stres Terhadap Perilaku Individu Dalam Lingkungan Kerja.

Dhania, Dini Rama. 2010. Pengaruh Stres Kerja dan Beban Kerja Terhadap Kepuasan Kerja Pada Medical Represectatif Kota Kudus. Jurnal Psikologi. Universitas Muria Kudus.

Hubeis, Musa dan M. Najib. 2014. Manajemen Strategik Dalam Pengembangan Daya Saing Organisasi. PT. Elex Media Komputindo. Jakarta.

Mangkunegara, Anwar Prabu. 2001. Manajemen Sumber Daya Manusia Perusahaan. PT. Remaja Rosdakarya. Bandung.

Muslihin. 2013. Memahami Definisi Operasional Dalam Penelitian.

Suharto dan Budi Cahyono. 2005, Pengaruh Budaya Organisasi, Kepemimpinan dan Motivasi Kerja Terhadap Kinerja Sumber Daya Manusia, di sekretariat DPRD Propinsi Jawa Tengah, JRBI. Vol. 1, No.1, januari 2005: 13-30.

Sunyoto, Danang. 2015. Penelitian Sumber Daya Manusia. CAPS (Centre of Academic Publishing Service). Yogyakarta.

Sunyoto, Danang. 2015. Manajemen Dan Pengembangan Sumber Daya Manusia (Dilengkapi dengan Budaya Organisasi, Pengembangan Organisasi, outsourcing). CAPS (Centre of Academic Publishing Service). Yogyakarta.

Sedarmayati. 2001. Sumber Daya Manusia dan Produktivitas Kerja. Mandar Maju. Bandung.

Syafri, Wirman dan Alwi. 2014. Manajemen Sumber Daya Manusia Dalam Organisasi Publik. IPDN Press. Bandung. Siagian, Sondang P. 2014. Manajemen Sumber Daya Manusia. Bumi Aksa. Jakarta.

U. Ummanah. 2012. Pengertian Beban Kerja. Repository.usu.ac.id. 